\title{
Thought on Improving Civic Awareness of Farmers
}

\author{
Chunyan Chen \& Shudong Zhang \\ School of Marxism, Changchun University of Science and Technology \\ Changchun 130022, China \\ E-mail: gaogeyongjin@sina.com
}

\begin{abstract}
For the time being, great gap still exists between the status quo of civic awareness of farmers and the requirement of construction of a new countryside in China. Thus, exploration into the path of fostering the civic awareness of farmers is an urgent task to construct the new socialist countryside.

Keywords: Farmers, Civic awareness, Fostering

Farmers are the subject of construction of a new socialist countryside. Fostering of the civic awareness of farmers is an important content and fundamental precondition to construct the new countryside. Modern civic awareness refers to democratic concept, right and obligation awareness, awareness of rule by law, cooperative awareness, independent personality and collective concept, etc, under the democratic system that people should have. This sort of awareness is the general ideological foundation for social subjective spirit and material life and is the basic foundation for social subject ideology and moral development. However, for the time being, great gap still exists between the status quo of civic awareness of farmers and the requirement of construction of a new countryside in China. Thus, fostering of the civic awareness of farmers is the urgent task for construction of the new socialist countryside.
\end{abstract}

\section{Value of fostering the civic awareness of farmers}

\subsection{Internal need to develop socialist market economy}

Marx pointed out, "Commodities are inherent levelers." Under the market economy, according to the law of value, objectively, exchange of equal values is required. In relationship of exchange of commodities, the subjects of exchange occupy equal status. Therefore, as far as exchange of goods is concerned, it is sufficient fulfillment of social equality. Fostering of the civic awareness of farmers and confirming the status of farmers' exchange subject and competitive subject is helpful for us to foster the most extensive and qualified market subjects, mould subjective factors of the market economy, improve socialist market economy and promote good and fast development of economy.

\subsection{Realistic appeal to improve the level of political participation of farmers}

The independent and equal spirit aroused by the civic awareness can enable farmers to make clear their social responsibility and social position, which in turn can stir up their political enthusiasm in participation in the national and social affairs. The political attitude and political participation of farmers is an important criterion to measure the democratic construction of Chinese socialist and is especially critical to construction of the system of self-governance for villagers. Strengthening the civic awareness of farmers can enlarge the number of farmers who participate in politics, expand the channel of farmers to participate in politics, improve farmers' political participation level, reinforce the strength of farmers' political participation, affect the policy formulation and implementation of the government and gain more interests for farmers.

\subsection{Important backbone to construct the new socialist country under the rule by law}

The civic awareness is an important bridge for the legal system to evolve from standardization to realistic order of rule by law. When the civic awareness of farmers generally awakens, they can form a common concept of "rule by law", which may make socialist democracy and legal system really put to practice, and make the idea of rule by law and legal system transfer to belief and norm of farmers in their life, which in turn is helpful to construct general and effective order of rule by law.

\section{Manifestations of deficiency of civic awareness of farmers at present}

\subsection{Deficiency of the subjective awareness of democracy}

The subjective awareness of democracy of villagers refers to recognition and attitude of villagers in the role they 
play in democratic and political life. Political participation is implementation of the subjective awareness of democracy of farmers. With opening of the society and improvement of economic level, political participation of farmers has obtained long term development. However, there exists great limitation to political participation behavior of farmers currently, which is manifested as below: firstly, in most cases, political participation of farmers is just instrumental. That is, they merely regard political participation as a tool to realize the need of certain interests and willpower. If they achieve a certain goal or they can not achieve a certain goal, it is probably that they do not participate in politics. Secondly, the political participation behavior of farmers at present is obviously influenced by non-institutional factors, such as sect, clan, personal likes and dislikes of voters, customs of villages, etc, and even bribery of voters, drawing on power of a clan, personal attack and writing of an anonymous letter to bring a false charge, etc, which all lead to direct obstruction to bring political participation of farmers in institutionalization and standardization. Only if farmers have the subjective awareness of democracy, can they actively participate in construction of the new countryside, get rid of narrow small-peasant consciousness, exercise the right of being the masters of the country and consciously assume the responsibility of developing rural democratic and political development.

\subsection{Weak awareness of right and obligation}

Farmers have inalienable basic rights of freedom and equality. With premise and guarantee of the constitution and law, as the uppermost component of Chinese citizens, just like townspeople, rural population and any member in the society, the mass farmers share the sacrosanct rights. Farmers should not only consciously be aware that they, like each citizen, have inalienable basic rights of freedom and equality, but that they should each assume corresponding and unshirkable social responsibility. Rights and social responsibility of farmers are inalienable, unavoidable and non-transferable. Farmers not only have the obligation and responsibility to take an active attitude in participating in public affairs related with public interests, but have the responsibility to approve, supervise and support public authorities, continuously improve work of the government and make the function of the government both in place and not off-side. However, for the time being, the various psychologies and behaviors of farmers in the process of self-governance for villagers reflect that a large majority of farmers still remain at the traditional thought of governance of villagers by officials, unaware that each individual has inalienable rights of freedom and equality as a citizen. In village election by farmers, many people have low evaluation on the leading group of their villages, indignant and with a lot of negative opinions, but they are lacking in participation enthusiasm in elections at the basic level. They are not willing to improve operation of power in the village by means of election, because they think election doesn't work at all. Quite a large majority of farmers are deficient in strong rights and obligation awareness and independent personality, unable to employ the rights of election entrusted by the nation in a correct way and not good at or bold in resisting various irrational requirements from the township government or clan by resorting to law, because they believe "the words of the lowly person carry little weight". Thus, they have no choice but to silently endure a lot of unfairness. Farmers are lacking in independent personality and sufficient awareness of rights, which causes development of self-governance for villagers based on political participation to lose its endogenous motive.

\subsection{Weak awareness of rule by law}

Generally speaking, the more and deeper a subject knows about the law and the closer his sentiment is with the law, the more rational his perception of the law will be and the more conscious his recognition, confidence, yearning and practice of law. Therefore, awareness of rule by law appears. In the traditional Chinese social political structure, law existed merely as dependency of the national power, and the traditional concept of governance by people has extremely deep influence upon farmers. Thus, it is a general phenomenon that farmers upheld power but were indifferent to law. In rural areas, the phenomena that power exceeds law and administration dominates law are common occurrence. Some law executors even consider themselves to be "the master" of power to abuse their position power or exceed their authority for administration, or having no power for administration. However, when legal rights of the common people are violated illegally, they have no idea, will or do not dare to resort to law. In the eye of quite a lot of farmers, they haven't established a belief in law and rule by law. Therefore, in most cases, "act in strict accordance with the law" is nothing but empty talk.

\subsection{Deficiency of cooperative awareness}

The most obvious characteristics of Chinese farmers is that they are good at separation, but not cooperation. Farmers do not have strong cooperative awareness and cooperation parties have obvious tendency of a clan. The fields of cooperation are narrow and the means of cooperation are single. There are various reasons that cause weak cooperative awareness. First of all, weak cooperative will of farmers is closely connected with the production, living and subsistence environment where they reside. The agricultural production with the unit of an 
individual family enables farmers to have the necessary means of subsistence without turning to others for help. Therefore, cooperation among farmers is weak. As a result of limitation of the rural social environment, low level of industrial and commercial development, small scale and small quantity, there are just a few cooperative projects that can be offered, which causes deficiency in practice of cooperation for farmers. Then, from the perspective of legal system, cooperation will necessarily lead to contradiction. However, the realistic legal system is not sound and is affected by the traditional culture, and people do not have strong awareness of legal system, so when contradiction occurs, they have no means to resolve it, with frequent fighting and unlawful violence, and even the incidents of families broken up. When contradiction occurs, cooperation must be affected in a negative way. Hence, quite a lot of people take the attitude of "the less trouble the better" and are not willing to cooperate with others.

\section{Paths to foster the civic awareness of farmers}

In the process of constructing the new socialist countryside, fostering the civic awareness of farmers is a complex project, which can not be finished in one day, but requires common efforts of the whole society. Generally speaking, we should vigorously develop rural economy, expand democratic practice and strengthen civic education.

\subsection{Vigorous development of rural economy is the basis to foster the civic awareness of farmers.}

Development of economy is the precondition for Chinese farmer awareness to transfer to civic awareness. Thus, we should vigorously develop socialist market economy, eradicate the small-peasant awareness of farmers and provide preconditions for generation of the civic awareness. First of all, only if we take the initiative to foster rural market environment, can we enable farmers to be thoroughly liberated from "natural bond" and "relationship of dependence", enable small peasants to change into "large peasants" who are involved in socialized commodity production and commodity exchange, enable farmers to change from domination by the nature ("submitting to the will of Heaven and "depending on Heaven for food") to domination by their labor products and domination of their own labor, to change from natural dependence relationship to social, overall and mutual dependence relationship, and to enable farmers to change from close natural awareness to open social awareness. Then, we should make sound the legal system of the market economy. Market economy is legalized economy. With continuous improvement of the legal system of market economy, it will certainly deepen people's understanding and knowledge in law and strengthen the awareness of rights among citizens, which is helpful for the subjects of the market and even members of the whole society to foster the positive spirit of abiding by the law and rational independence spirit. In the meantime, market economy activities also has important effect on cooperative awareness, reciprocity awareness, credit awareness and self-discipline awareness of subjects of the market, and have demonstration effect on the whole society and public.

\subsection{Expansion of democratic practice is the foundation to foster the civic awareness of farmers.}

Fostering of the civic awareness of farmers ought to be based on practice. Without accumulation of experiences in a democratic life, it is difficult to form mature civic awareness. In the process of constructing the new socialist countryside, it is our task to enable village farmers to really establish positive political participation awareness and political conviction and political sentiment in the socialist career through the socialized political and cultural channel with Chinese characteristics, to enable them to strengthen understanding in political process and political life in various political participation practice and intensify feeling of recognition and feeling of responsibility in political systems both inside and outside the villages, to cultivate the civic awareness of farmers and to let farmers form personal experience in political participation. Currently, the villages should carry out the democratic management system of making village affairs more transparent by means of improving the system of "One Project One Discussion" of villagers and further standardizing the system of elections at the basic level, absorb actual participation of farmers, and let farmers form personal democratic experience at the time of learning to vote in voting and learning to administer in administration. In this way, it is not only likely to really change traditional politics and culture and the accompanied behavioral mode and psychological tendency in democratic practice, but is likely to exercise the democratic and administrative ability of farmers without consciousness, improve their enthusiasm in political participation, enable farmers to get familiar and accustomed with operation process of democracy step by step, stimulate a sort of tolerance and compromise spirit exercised based on long term democracy at the grass-root level, and foster democratic, rational and dependent civic awareness.

\subsection{Strengthening civic education is the key to foster the civic awareness of farmers.}

It involves a lot of work to do to realize transfer from "villagers" to citizens of Chinese farmers, but education is the entry point to resolve all problems. Education has direct promotion effect both in initiating economic growth 
and improving quality of farmers. Civic education refers to education influences imposed on the civic awareness to make citizens come to realize the social responsibility and social mission that they should burden, without external enforceability at all, to attain a rational and conscious state. In political education for citizens, pure political preach should be changed to cultivation of democratic political awareness and democratic participation capacity; in moral education, empty moralization and inculcation should be changed to enlightenment of personal moral conscience and fostering of moral personality, in which we should cultivate independence awareness and independent personality of social members and their team awareness and public moral awareness; in legal education, pure education of knowing the laws and abiding by the law should be changed to formative education of the concept of rights and concept of freedom. Especially, we should let citizens understand the essence of a modern country, make clear demarcation between rights and power and the concepts of market economy, democratic politics and modern politics, and direct and strengthen citizens' reflection and approval of the national system and legal system. Only if we perseveringly carry out civic education and improve educational methods and means, can farmers with modern civic awareness join in the team of citizens in a steady flow and can they lay a strong and firm foundation for a modernized and democratic society under the rule of law.

\section{References}

Qiu, Guoliang \& Duan, Yanfeng. (2008). Choice of Construction of the New Countryside and Path of Fostering Civic Awareness of Farmers. JOURNAL OF JIANGXI ADMINISTRATION INSTITUTE, (4).

Zhan, Lili. (2008). Tentative Analysis of Issues of Fostering Civic Awareness of Farmers. ECONOMIC RESEARCH GUIDE, (15).

Zhao, Ping. (2006). The fostering of peasant's awareness of citizens' obligations: The essential approach to the construction of new rural area. Higher Agricultural Education, (11).

Zhu, Baiwei. (2007). Civic Awareness in Modernization Process of China. Economic and Social Development, (3).

Zhu, Ningfeng. (2004). Farmers' civil consciousness and its influence on villagers' autonomy. JOURNAL OF GUANGDONG COLLEGE OF YOUNG CADRES, 18(3). 